\title{
Ending Plagiarism: Using Technology to Scaffold Article Review and Effective Source Material Integration into Student's Work
}

\author{
Alex Monceaux ${ }^{*}$ \\ TIEP at Lamar, Lamar University, Beaumont, USA \\ *Corresponding author: alex.monceaux@tiec.org
}

Received March 23, 2015; Revised May 21, 2015; Accepted May 26, 2015

\begin{abstract}
This document illustrates how to 1) engage students in active research, 2) scaffold the student's accurate review of articles for pertinent source material, and 3) integrate that material into the student's work to hone student's research and analysis skills, bolster writer confidence, and avoid plagiarism.
\end{abstract}

Keywords: innovation, technology, research, scaffolding, composition

Cite This Article: Alex Monceaux, "Ending Plagiarism: Using Technology to Scaffold Article Review and Effective Source Material Integration into Student's Work.” American Journal of Educational Research, vol. 3, no. 6 (2015): 736-741. doi: 10.12691/education-3-6-11.

\section{Introduction}

In 1892, a young Helen Keller published her short story The Frost King, which strangely resembled Margaret T. Canby's The Frost Fairies. Upon these realizations, Keller [1] was dragged into a tribunal at her school, Perkins Institute for the Blind, was tried, and was narrowly acquitted - the effect lasted long after. David Boles [2] writes that this single event "haunted and stooped her for the rest of her life."

Keller [1] writes:

"The young writer, as Stevenson has said, instinctively tries to copy whatever seems most admirable, and he shifts his admiration with astonishing versatility. It is only after years of this sort of practice that even great men have learned to marshal the legion of words which come thronging through every byway of the mind.

I am afraid I have not yet completed this process ... I cannot always distinguish my own thoughts from those I read ... what I read becomes the very substance and texture of my mind.... Compositions are made up of crude notions of my own, inlaid with the brighter thoughts and riper opinions of the authors I have read.... The great difficulty of writing is to make the language of the educated mind express our confused ideas, half feelings, half thoughts, when we are little more than bundles of instinctive tendencies. Trying to write is ... put a Chinese puzzle together. We have a pattern in mind... but the words will not fit the spaces, or ... will not match the design.

It is within the crux that this discussion is taken up: how are writer's voices formed, how is confidence constructed, how is the academic writer fashioned? We are to understand that such fraud will always endure, but that for others, facing and suffering such an event haunts and dogs their psyche often robbing them of their voice and rendering talented scholars inert.

Plagiarism is not new, it's not going away, and it contains huge consequences. Fourth century Cicero [3] differentiates between legitimate imitation and theft in Naevis' and Ennius' writings, linking the motivation to hide that one is drawing from another source equals theft. Recently, Kentucky Senator Rand Paul [4] was accused of pulling sections of his book and speech material from Gattaca and Wikipedia. Whitley's [5] 1998 study indicated academic dishonesty's prevalence at 70\%. Ina 2005 [6] UK study, 46\% of undergraduates reported copy/pasting whole paragraphs without in-text citations; $23 \%$ report having done so several times. Further, while the extent of plagiarism is epidemic, the consequences, mostly hidden, can be equally devastating. Plagiarism Today [7] post on high profile plagiarism cases, two of which are: Jayson Blair, the New York Times resigned after an investigation revealed about half of his articles contained instances of "plagiarism, fabrication, and unethical behavior" and Lloyd Brown, editor for the Florida Times-Union resigned in 2004 after an investigation revealed several plagiarism incidents and has yet to recover. This is a small list, one could find extensive example in literature, computer gaming, academia, music, visual arts, and politics as well. Those caught often suffer greatly, publicly, and for extended periods; often then offences create roadblocks to career aspirations to emerging leaders. Unfortunately, the consequence cannot be confined to the individual committing the offence, often a single incidence opens the door to question every researcher even when their work meets the highest standards [8].

The nature of plagiarism is often questioned as well What is plagiarism, Are there varieties and should these 
varieties contained varied consequences, and How does one differentiated between these plagiarized incidents? Epstein [8] points to the University of Chicago's Policy on Academic Fraud (1998) definition of Academic Dishonesty as involving.

"a deliberate effort to deceive and is distinguished from an honest mistake and honest differences in judgment or interpretation ....plagiarism; fabrication or falsification of evidence, data or results; the suppression of relevant evidence or data; the conscious misrepresentation of sources; the theft of ideas; or the intentional misappropriation of the research work or data of others."

Epstein [8] points out the two types of wrongs herein to separate plagiarism from academic fraud: 1) a misinterpretation or representation of data, twisting of data to prove one's point, which then ask the community to work with false data, wasting time and resources; 2) plagiarism - misappropriation, which offers true information to seeks to provide an undeserving person "recognition, promotion, and rewards." As one could clearly see the consequence of these two wrongs clearly differ, but the greater questions is how empower researchers and writers to avoid such pitfalls. To do this, educators must consider how emerging writers are preparing data, which Epstein [8] suggest starts with question the intention: "the deliberate fabrication of omission of data [and] progresses to recklessness - the preparation of data without knowing or caring whether it is true or false" and must end with a technical writing knowledge base for an accurate written production.

Due to sure a high prevalence, many have sought to discover who plagiarize; studies have been done on plagiarism and gender, race, ethnicity, criminality, privilege, morality, and many other factors - three factors seem to cut across all other variables and provide adequate leverage for educators to produce stop-gaps that can rectify emerging issues at their onset: motivation, knowledge, and confidence. Motivation deals with the writer's willingness to actively engage with the material in an authentic manner - some simply do not want to complete the work and offer another's work as their own, others, seek rewards that seem out of their grasp, thus they misappropriate, or twist data. This last problem largely deals with the student's ability, which can be bolstered through mentorship and education. The coupled with practice can alleviate a third issue, confidence and bolstering the emerging scholar identity. The effective mitigation of these three areas can effectively detour many unintended emerging writers from major career setbacks while establishing a system to deny wrongly motivated writers opportunity into the arena.

\subsection{Student Motivation}

There will always be students who are not interested in writing, or the course work. There are a litany of reasons, some plausible, others excusable, others reprehensible; however, in a system that dictates that students perform certain requirements as specific levels/proficiencies to attain a qualification, there will be those who baulk, if only for spite and or spirit.

Gullifer and Tyson [9] present literature from forensic psychology that suggests that the individual perspective and motivation enable one to affect positive change to an intervention. Byrne and Trew [10] write: “"to be effective, interventions that aim to reduce or prevent offending behavior need to be based on a sound understanding of what leads people to offend, and what leads people to stop offending."

However, often in the population this study involves, the motivation to plagiarize - via copy/paste or purchased papers - is often linked to poor time management and or the student's perception of the material's or assignment's relevance to his/her academic achievement. In this case while an educator and fully understand, the greater point is that it is required for which ever reason the institution as deemed necessary and the student must complete the objectives as set forth to obtain the desired end- a certificate, diploma, or degree. During this study, student/faculty consultation rarely was able to mitigate these issues, however, this knowledge created awareness for both the educator and the student of the student's desire to escape the assignment.

To this end, establishing clear delineations of plagiarism and it' consequences in addition to detection approaches and honor codes can be effective in warding off plagiarized submissions. Gillifer and Tyson [9] cite several US surveys illustrating the effectiveness of honour codes: (McCabe and Bowers 1994; McCabe and Treviño 2002; McCabe, Treviño, and Butterfield 2001) - in these studies, institutions with honor codes had significantly lower levels of academic dishonesty and plagiarism than those that did not have honor codes. However, detection software may only change the student's mode of plagiarism, i.e. reduce cut/paste options for un-cited paraphrasing [9].

\subsection{Student Knowledge}

However, many other students lack motivation due to lack of knowledge. Gullifer and Tyson [9] report on a 1997 study by Roig Studies in Higher Education 465 that "clearly demonstrated that more than half of the students in their study could not identify clear examples of plagiarism, indicating that, whilst policy may exist, students have little knowledge or understanding of it." Thus, student knowledge is critical for student success.

Elander, et al, [11] suggest that students be instructed on what plagiarism is, the reasoning behind it's forbiddance, and its consequences, but that a more effective cure is beyond provision of basic information, however, to prevent plagiarism more effectively, institutions must go further than providing that kind of basic information, i.e., providing instructional that builds the student's writing.

Valentine [12] suggests that plagiarism may operate outside of the binaries of ethics and morality and suggest that such a position could negatively affect a student's ability to apprehend and develop academic writing skills as such judgments shut off the students' chance to practice citation and honest performance when an error is interpreted singularly as dishonesty instead of a level of understanding of the individuals' approach to entering a new discourse.

Several studies demonstrate student related challenges involving paraphrasing and plagiarism [13,14] and other studies [15] found paraphrasing exercise help mitigate these challenges, just as citation exercises [16] decrease 
student issues involving wrongful citation practices. Elander [11]suggested that such interventions assist in enabling the students to avoid errors leading to unintentional plagiarism, but according to Warn [17] may create a greater issue with students who intend to cheat as better paraphrasing decreases the odds of software catching intentional misappropriation of information and fraud.

\subsection{Student Confidence}

Perhaps one of the largest issues in student academic writing is the student's identity - the student writer is called upon to be both a student while performing as an academic writer. This involves much more than the technical skills required to write - Elander [11] et al takes up the discussion on identity and suggest that this is a twofold process, one involving the author's identity of himself and one that he actively constructs in his writing leading to concerns that students may unintentional plagiarize due to a student's not or inability to adequately take on the authorial identity, i.e., the student understanding his/her having a unique and important voice that engages in the discourse and offers a relevant contribution to the discourse.

Liu, et al [18] in studying cultural differences suggest Eastern education typically leads itself to these issues due to cultural structures that focus knowledge and authority in the instructor and discourage students from questioning those authoritative sources, thus keeping the students outside of any critical engagement with the sources. This then compels the student to simply adopt views held by those in power, rather than questioning and challenging those notions -i.e., the student sees copy and paste as a safer, more viable option as it removes them from cultural stigmatization involved in questioning authorities and offers views of authorities.

Reason et. al. [19] suggest that there are several components involved in student development that Higher Education needs to focus on, these involve teaching students to strive for excellence, cultivate academic integrity, contribute to a larger community, to take the perspective of other's seriously including respecting different views, gathering evidence to support ideas, considering diverse perspectives, reconsidering one's own perspective, and exploring diverse perspectives, cultures, and worldviews.

\section{Objectives}

The objectives of this study was to 1 ) engage students in active research, viz., a) the students interacted with the articles, questioning the content and authorship in relation to the article's relevance to their specific study, b) explored in what ways an article did or did not supported their thesis and points; 2) facilitating structured and increasingly high pressured assignments to maintain the challenge level, and increase academic rigor; 3) bolster student's technical knowledge of a) the academic writing process, b) research process and skills, 4) increase student's specific content knowledge.

The researcher's purpose was to, in a low-stakes manner, aid in the development of scholar identity, writer's voice, while building technical competences and the student's knowledge base.

Following is a description of the intensive writing program in which the students engaged and the manner in which they engaged to reach the objectives.

\section{Methods}

This course used an LMS (Schoology.com) to couple the writing process with the article and source reviews. The course lasted 15 weeks and each student was assigned six writing assignments each integrating peer-reviewed articles. Each assignment increased in the word count, sources, and integrated material. Additionally, each assignment focused on the same general topic, but required the student to approach the topic using a different analytical mode, i.e., process, cause, effect, compare, contrast, etc., and to offer a clear connection to the previous assignments in a manner that would allow the combined works to fit together well or to model a thesis or dissertation. Once a student had picked a topic, the following methods would be invoked to alleviate plagiarism.

\subsection{Article Review: Finding Suitable Material}

The first step required the student to find and review articles to support their topic. The article review process was an adaptation of the C.R.A.P. Test (Current, Reliability/Relevance, Authority, Purpose /Point of View) to an online format into a "quiz" format for the students. Researchers added three sections: Source Information, Source Summary, and Use to guide students through the article review.

The first section, Source Information sought a hyperlink and the source title enabling the instructor to review the article with the student. Secondly, the student assessed the article for its currency - less than five years old or historically relevancy. Third, the student reflected on the articles Reliability and Relevance answering the following questions: Is it a primary or secondary source?; Are the methods or references provided?; Who published the information?; Was it peer reviewed? - (You may not use non-peer reviewed sources); Does all of the information apply to your topic, or only part of it; which part?; Is the information general or detailed - how so?; Is the information balanced or biased - how so? Fourth, students evaluated the Authority of the author thought the following questions: Was it a single person or several? (Give the name/s); Was it a corporation or organization? (Give the name); Are their credentials provided? - (list them); What is their reputation or expertise (major field of study/research)? Fifth, students considered the author's Purpose and Point of View in the following responses: Who is the intended audience?; Is the information intended to inform, explain, convince (argue), persuade, sell, entertain, ... - identify which?; Is this a first-hand account of an event or research?, Does the author have a vested interest in the topic? Sixth, students briefly summarized the article using the following framework: 1 . Citation: Introduce the title, author, source, and the publication date; 2. Thesis Statement: In one sentence, 
state the authors topic and major comments or positions on that topic; 3. Supporting Ideas: Cover all the author's major points and the relationships between those ideas. Omit specifics and personal opinions, but include the author's purpose - inform, explain, persuade, entertain, sell, etc., Grammar \& Mechanics: Use you own words - no direct quotes. Effectively use transitions. Check your grammar, punctuation, and spelling. Limit your word count to $150-200$ words. Lastly, students indicated specifically how this article was of use to their study by linking the article directly to the sentence outline they had already produced: How do you plan on using the article? Which paragraph/s will you use it for? Which controlling ideas does it support? Working through this question set for each article embedded the necessary questions in the student's minds and seeks to teach them to review articles thoroughly prior to their using those articles. This question set creates a uniform way to question articles relevance to one's work, and helps to establish a sense of power in the writer through his active judgments and reflections on the article. The instructor serves as a mentor/guide to ensure that students are rigorously engaging and judging the text for its specific value in their work, and gives specific feedback to the student in areas that the student is not adequately reviewing the material or is submitting erroneous responses.

Table 1. Article Review

\begin{tabular}{|c|c|}
\hline \multicolumn{2}{|r|}{ Scaffolded Article Review } \\
\hline Concept & Guiding Questions \\
\hline Source Information & $\begin{array}{l}\text { - Hyperlink } \\
\text { - Source Title - If you are using a chapter or section, provide both }\end{array}$ \\
\hline Current & $\begin{array}{l}\text { - Has it been published in the last five years? } \\
\text { - If you have a historical research topic, was it published around the date of the original event? }\end{array}$ \\
\hline Reliability / Relevance & $\begin{array}{l}\text { - Is it a primary or secondary source? } \\
\text { - Are the methods or references provided? } \\
\text { - Who published the information? } \\
\text { - Was it peer reviewed? } \\
\text { (You may not use non-peer reviewed sources) } \\
\text { - Does all of the information apply to your topic, or only part of it; which part? } \\
\text { - Is the information general or detailed - how so? } \\
\text { - Is the information balanced or biased - how so? }\end{array}$ \\
\hline Authority & $\begin{array}{l}\text { - Was it a single person or several - give the name/s } \\
\text { - Was it a corporation or organization - give the name } \\
\text { - Are their credentials provided - list them } \\
\text { - What is their reputation or expertise (major field of study/research) }\end{array}$ \\
\hline Purpose/Point of View & $\begin{array}{l}\text { - What was the intent of the author, and how is the author connected to the information? } \\
\text { - Who is the intended audience } \\
\text { - Is the information intended to inform, explain, convince (argue), persuade, sell, entertain, etc. - identify which? } \\
\text { - Is this a first-hand account of an event or research? } \\
\text { - Does the author have a vested interest in the topic }\end{array}$ \\
\hline Source Summary & $\begin{array}{l}\text { - Citation: } \\
\text { (Introduce title, author, source, and publication date) } \\
\text { - Thesis Statement: } \\
\text { (In one sentence, state the authors topic and major comments or positions on that topic) } \\
\text { - Supporting Ideas: } \\
\text { (Cover all the author's major points and the relationships between those ideas. Omit specifics and personal opinions, but } \\
\text { include the author's purpose - inform, explain, persuade, entertain, sell, etc.) } \\
\text { - Length: } 150 \text {-200 words } \\
\text { - Grammar \& Mechanics: } \\
\text { (Use you own words - no direct quotes. Effectively use transitions. Check your grammar, punctuation, and spelling.) }\end{array}$ \\
\hline Use & $\begin{array}{l}\text { - Which paragraph/s will you use it for? } \\
\text { - Which controlling ideas does it support? }\end{array}$ \\
\hline
\end{tabular}

\subsection{Source Material Integration: Mining Material for Relevant Data}

One of the greatest challenges with student academic writing is the source integration into the student's work. Students may know well enough how to locate articles, but mining those articles for appropriate material and properly appropriating that material has been a critical challenge according to the literature. Additionally, when students are able to locate source material, many of them struggle to integrate that material into their work.

The second step is to have the students return to the article they have reviewed, and using their sentence outlines, reflect on how particular passages fit their discussion, what the passage means, and where the passage can be used in their work to best support their ideas. Researchers created another quiz with four general categories for query: the source, quote, use, and meaning, each with several questions.
Table 2. Source Material Integration

\begin{tabular}{|c|c|}
\hline \multicolumn{2}{|r|}{ Source Material Integration } \\
\hline Your Source & $\begin{array}{l}\text { - Provided a hyperlink to your journal } \\
\text { - List the author/s name/s } \\
\text { - List the title of the work (if you are using a book } \\
\text { chapter, list the book title and the chapter title) }\end{array}$ \\
\hline Your Quote & $\begin{array}{l}\text { - Using quotations marks ("/") and in-text citations } \\
\text { (Holmes 456), write out your intended quote. } \\
\text { - Identify the type of supporting detail this quote } \\
\text { contains. (If your quote is not one of these, Do Not } \\
\text { Use It!)(fact, examples, causes, reasons, anecdote) }\end{array}$ \\
\hline Quote Use & $\begin{array}{l}\text { - Where will you use this quote (intro, body } 1,2,3, \ldots, \\
\text { conclusion)? } \\
\text { - Which specific point (idea) does this quote support } \\
\text { in your paper? }\end{array}$ \\
\hline Quote Meaning & $\begin{array}{l}\text { - Explain what this quote means. } \\
\text { - Paraphrase or Summarize this quote (put it into } \\
\text { your own words). If you can accurately explain the } \\
\text { quote, you should not use the direct quote, use your } \\
\text { paraphrase or summary instead. }\end{array}$ \\
\hline
\end{tabular}

The first question request the hyperlink, author's name, and title of the work. The second steps practices direct 
quotations and the use of in-text citations; the student is to cut and paste the quote into the LMS with quotation marks and an in-text citation. This is to reinforce that direct quotes necessitate both quotation marks and in-text citations. Thirdly, the students indicate the exact paragraph they intend to use the quote and how they intend to use the quote, i.e. which controlling idea this specific quote supports. In this way, the instructor is able to understand the logic behind the quote, evaluate the student's technical knowledge on using direct quotes/intext citations. Lastly, students must paraphrase or summarize the quote the explain what the quote means using only their words. This last step effectively pulls the student away from direct quote usage and affords the instructor the ability to comprehend the student's comprehension of the text and ability to synthesis the text in a meaningful manner.

\subsection{Pulling It Together: Engaging Emerging Writers}

After students have reviewed the article, located and synthesized the specific quotes effectively, they are then able to drop these in to the sentence outline and draft a paper that both presents their unique ideas, but supports those ideas using a variety of sources.

This draft is submitted as a first draft for review and feedback and is the second step of the student's writing process for each of the six writing assignments.

\section{Results}

This process has effectively stopped plagiarism in the courses that follow this method. This two dimensional stop-gap method makes it impossible to purchase a completed paper and makes it complicated for someone other than the student to complete each of the steps logging in to the LMS, completing work, and responding to feedback. To purchase a paper, the student would still have to dissect the paper to provide the article reviews and source material review.

Considering the student's quality and quantity of work, both have increased. Submission totals, the six assignments combined, range in length from 30-50 pages, utilize twenty-one plus peer-reviewed sources, and dozens of in-text citations. Further, the quantity of direct quotations has dramatically reduced as students begin to synthesize the material into their own words in their work better.

Furthermore, data from the test revealed student proficiency in completing the article reviews as reducing from more than an hour per article to five-ten minutes per article. As students understanding of what material should be considered, how and where to find that information solidified, their ability review the articles quickened as well as their understanding of the article.

Additionally, students learned how to find information not published in the article to consider authorial expertise and detect biases. Often an article may not provide adequate information on the author/s for the student to answer the questions forcing the student to search the web and other material the author has produced.

\section{Discussion}

The objectives of this study were to 1 ) engage students in active research, viz., a) the students interacted with the articles, questioning the content and authorship in relation to the article's relevance to their specific study, b) explored in what ways an article did or did not supported their thesis and points; 2) facilitating structured and increasingly high pressured assignments to maintain the challenge level, and increase academic rigor; 3) bolster student's technical knowledge of a) the academic writing process, b) research process and skills, 4) increase student's specific content knowledge.

The results demonstrate that this process is effective in getting the students to engage in the literature, reading it, synthesizing it, and questioning the way that the article did or did not fit into the scope of their studies. Further, scaffolding the article reviews provided an effective path for the students to gradually increase the quality and quantity of their productions, within the same time limits that they had produced lesser compositions. I.e., this method not only successfully scaffolded article reviews and source material integration, but student time management also.

Reflecting on the student compositions, the student's technical researching and writing skills dynamically improved. The use of repetition created systems that became comfortable, memorable, and more easily implemented into each piece rather than the student having to "start over" each time. Student reported greater confidence in their research ability as well as their willingness to engage in research activities. Additionally, they reflected in disbelief at the amount they had learned, read, discussed, and written in one semester. Thus, in the end, the students found that they had a much more than a conversational knowledge of their topic, but due to the varied methods of analysis, the amount of research and reading they had completed, and the discussion they had facilitated, they had mastered their topics.

\section{Conclusion}

Stevenson reported that Hellen Keller [1] wrote: "There is no way to become original, except to be born so, and although I may not be original, I hope sometime to outgrow my artificial, periwigged compositions. Then, perhaps, my own thoughts and experiences will come to the surface. Meanwhile I trust and hope and persevere, and try not to let the bitter memory of "The Frost King" trammel my efforts."

The profound result of this experiment is that students begin to learn that they are original, that they have valuable ideas begging to be heard, that are valid and relevant to the discourses the students are involved in. And while it is true those ideas are shaped largely by their cultures, what they read, and their experiences, they learn that they can, through diligence and attentiveness, emerge as authentic voices that present valuable, relevant information today.

\section{Acknowledgement}

I wish to thank TIEP at Lamar and James Moore, Director - TIEP at Lamar, for their support for this project. 


\section{References}

[1] H. Keller, (2015) “The Story of My Life,” 2015 American Foundation for the Blind. [Online]. Available: http://www.afb.org/MyLife/book.asp?ch=P1Ch14. [Accessed 17 January 2015].

[2] D. Boles, (27 January) 2014 "David Boles Blogs: Liberal Mindset, Conservative Morality," [Online]. Available: http://bolesblogs.com/2014/01/27/the-frost-king-defending-helenkeller-and-other-non-superhuman-deaf-blind/\#comments. [Accessed 17 January 2015].

[3] S. McGill, (2012) "Chapter 1 The Aancient and the Modern: Approaching Plagiarism," in Plagiarism in Latin Literature, Cambridge, Cambridge University Press, p. 256.

[4] S. Contorno and J. Kliegman, (2013) "'Rachel Maddow says Rand Paul's 'Gattaca' Speech 'Was Totally Ripped off of Wikipedia"'," PolitiFact (Tampa Bay Times), Tampa Bay.

[5] B. E. Whitley, (1998) "Factors Associated with Cheating Among College Students: A Review.," Research in Higher Education, vol. 39, pp. 235-274.

[6] R. Bennet, (2005) "Factors Associated with Student Plagiarism in a Post-1992 University.," Assessment \& Evaluation in Higher Education, vol. 30, p. 137-62.

[7] J. Bailey, (2012) "Plagiarism Today," [Online]. Available: https:/www.plagiarismtoday.com/2012/08/21/5-famousplagiarists-where-are-they-now/. [Accessed 19 Jan 2015]

[8] R. Epstein, (2010) "Academic Fraud Today: It's Social Causes and Institutuional Responses," Stnaford Law \& Policy Review, vol. 21, pp. 135-154.

[9] J. Gullifer and G. A. Tyson, (2010) "Exploring University Student's Perceptions of Plagiarism: A Focus Group Study," Studies in Higher Education, vol. 35, no. 4, pp. 463-481.
[10] C. F. Byrne and K. F. Trew, (2005) "Crime Orientations, Social Relations and Involvement in Crime: Patterns Emerging from Offenders' Accounts.," The Howard Journal of Criminal Justice, vol. 44, no. 2, pp. 185-205.

[11] J. Elander, G. Pittam, J. Lusher, P. Fox and N. Payne, (2010) "Evaluation of an Intervention to Help Students Avoid Unintentional Plagiarism by Improving Their Authorial Identity," Assessment \& Evaluation in Higher Education, vol. 35, no. 2, pp. 157-171.

[12] K. Valentine, (2006) "Plagiarism as Literacy Practice: Recognizing and Rethinking Ethical Binaries," College Composition and Communication, vol. 58, pp. 89-109.

[13] M. Roig, (1997) "Can Undergraduate Students Determine Whether Text has been Plagiarized?," Psychological Record, vol. 47, pp. 113-122.

[14] M. Roig, (1999) "When College Students' Attempts at Paraphrasing become Instances of Potential Plagiarism.," Psychological Reports, vol. 84, pp. 973-82.

[15] J. P. D. a. J. A. Landau, (2002) "Methods for Helping Students Avoid Plagiarism," Teaching of Psychology, vol. 29, no. 2, pp. 112-5.

[16] P. Schuetze, (2004) "Evaluation of a Brief Homework Assignment Designed to Reduce Citation Problems," Teaching of Psychology, vol. 31, no. 4, pp. 257-9.

[17] J. Warn, (2006) "Plagiarism Software: No Magic Bullet!," Higher Education Research and Development, vol. 25, pp. 195-208.

[18] X. Liu, S. Liu, S.-h. Lee and R. J. Magjuka, (2010) "Cultural Differences in Online Learning: International Student Perceptions," Educational Technology \& Society, vol. 13, no. 3, pp. 177-188.

[19] R. D. Reason, A. J. Ryder and C. Kee, (2013) "Higher Education's Role in Educating for Personal and Social Responsibility: A Review of Existing Literature," NEW DIRECTIONS FOR HIGHER EDUCATION,, vol. Winter, no. 164, pp. 13-22. 